\title{
DETERMINANTS OF LATENT TUBERCULOSIS IN BANDUNG, WEST JAVA
}

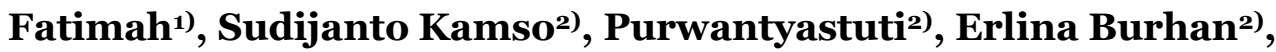 Bachti Alisjahbanas)}

\author{
1)Pengayoman Hospital, Ministry of Law and Human Rights \\ 2) Faculty of Public Health, University of Indonesia \\ 3)Faculty of Public Heath, Padjajaran University
}

\begin{abstract}
Background: TB remains a leading cause of morbidity and mortality in developing countries, including Indonesia. About $7 \%$ of all deaths in developing countries are attributed to TB. Latent tuberculosis infection (LTBI) is a state of persistent immune response to stimulation by Mycobacterium tuberculosis antigens without evidence of clinically manifested active TB. This study aimed to examine the determinants of latent tuberculosis in Bandung, West Java.

Subjects dan Method: This was a cross-sectional study conducted in Bandung, West Java. A total of 252 peoples were selected for this study, consisting of latent tuberculosis cases and controls. The dependent variable was latent tuberculosis. The independent variables were age, nutrition status, BCG scar, and smoking. The data were collected by laboratory test and questionnaire. The data was analyzed by a multiple logistic regression.

Results: The risk of latent tuberculosis increased with occasional smoking ( $\mathrm{OR}=$ 9.34; $95 \% \mathrm{CI}=4.23$ to 20.67$)$, frequent smoking $(\mathrm{OR}=12.99 ; 95 \% \mathrm{CI}=2.49$ to 67.94), poor nutrition status $(\mathrm{OR}=2.64 ; 95 \% \mathrm{CI}=0.49$ to 14.31$)$, but decreased with BCG scar (OR=0.45; 95\% CI=0.21 to 0.95).

Conclusion: The risk of latent tuberculosis increases with occasional smoking, frequent smoking, poor nutrition status, but decreases with BCG scar.
\end{abstract}

Keywords : latent tuberculosis, smoking, nutrition status, BCG scar.

\section{Correspondence :}

Fatimah. Pengayoman Hospital, Ministry of Law and Human Rights, Jl. Raya Bekasi Timur No. 170B, Jakarta Timur. Email: jengfatie@gmail.com.

Mobile : 081288898088 